Córima, Revista de Investigación en Gestión Cultural

ISSN electrónico: 2448-7694

Universidad de Guadalajara

Sistema de Universidad Virtual

México

corima@udgvirtual.udg.mx

Año 4, número 7, julio-diciembre 2019

\title{
Tejer escenarios de paz desde la Gestión Cultural
}

\author{
Leidy Tatiana López Saldarriaga ${ }^{1}$ \\ Leidy Marcela Castaño Bermúdez \\ Tatiana Grisales Rios \\ Universidad Nacional de Colombia, Colombia
}

DOI: $10.32870 /$ cor.a4n7.7342

[Recibido: 11/04/2019; aceptado para su publicación: 17/05/2019]

\section{Resumen}

En Colombia, sus distintas regiones han sido escenarios de violaciones a los derechos humanos. Sus habitantes han tenido que reconstruir su proyecto de vida, ejercer su autonomía para resistir, resanar y reconstruir realidades. Desde la Gestión Cultural comunitaria y el emprendimiento cultural, las comunidades han revitalizado sus principios de colectividad, unidad y autonomía, han diseñado sus propias formas de gobernanza local y han encontrado en sus territorios instrumentos y oportunidades para propiciar el desarrollo comunitario e individual. En el marco del proyecto "Fortalecimiento institucional a organizaciones sociales y culturales que trabajan en la construcción de paz en la subregión Norte y Occidente del departamento de Caldas" se llevó a cabo un proceso de

\footnotetext{
${ }^{1}$ Correo electrónico: Itlopezs@unal.edu.co
}

CÓMO CITAR ESTE ARTÍCULO:

López Saldarriaga, L.T., Castaño Bermúdez, L.M. y Grisales Rios, T. (2019). Tejer escenarios de paz desde la Gestión Cultural. Córima, Revista de Investigación en Gestión Cultural, 4(7). doi: $10.32870 /$ cor.a4n7.7342 
formación y dinamización comunitaria con colectivos y emprendimientos culturales que trabajan en la construcción de paz de los municipios de Anserma, Viterbo y Aguadas (Caldas). A través de metodologías colaborativas y de diversas estrategias de la gestión cultural se fortalecieron los procesos de gestión, administración y comunicación de 30 iniciativas culturales y sociales, lo que facilitó su estructuración y proyección; esta fue una experiencia para reconocer el poder y la fuerza del quehacer cultural en la construcción de paz.

\section{Palabras clave}

Construcción de paz, gestión cultural, emprendimiento cultural, emprendimiento social, resiliencia.

\section{Introducción}

En este artículo se revisa la relación entre el emprendimiento cultural y social, así como los procesos de resiliencia y desarrollo de las comunidades para la generación de un impacto positivo en territorios de posconflicto, a partir de la experiencia obtenida en el proyecto para lograr el fortalecimiento institucional de organizaciones sociales y culturales que trabajan en la construcción de paz en la subregión norte y occidente del departamento de Caldas, denominado "Fortalece Cultura Caldas". Este proyecto fue liderado por el área de Gestión y Comunicación Cultural en el marco del programa Extensión Solidaria de la Universidad Nacional de Colombia, sede Manizales; se desarrolló entre agosto de 2017 y noviembre de 2018 con el propósito de fortalecer los procesos organizativos y de gestión de emprendimientos sociales y culturales de los municipios de Aguadas, Anserma, Viterbo y Caldas.

A través de talleres grupales y asesoría personalizada se brindaron herramientas de administración, gestión cultural y comunicación, al mismo tiempo se implementaron métodos de trabajo colaborativo para que los participantes reconozcan los agentes de su sector y los procesos que desarrollan, además de intercambiar conocimientos, ideas y crear una red contactos. Se generaron espacios de networking denominados "El café cultural", "La colmena" y "Tejidos" con el propósito de que los emprendedores compartan sus necesidades y avances, construyan alianzas interinstitucionales, realicen intercambios efectivos, de largo alcance, y que generen redes de trabajo para la sostenibilidad de sus proyectos de emprendimiento, cuyos resultados impactarán a nivel local y regional.

Con los resultados obtenidos en este proyecto se espera que los emprendedores sociales y culturales logren consolidar su iniciativa y proyectarla para que continúen, bajo condiciones de trabajo digno, transformando los 
problemas sociales, ambientales y culturales y aportando al desarrollo social y económico de sus territorios al generar oportunidades de trabajo y de crecimiento integral para sus comunidades.

Según Bargsted (2013), el emprendimiento social "Implica elaborar, ejecutar y sustentar iniciativas orientadas a la superación de una dificultad social, y el logro de un beneficio común a un grupo humano, ya sea por medio de actividades empresariales o social-comunitarias" (p.122). Este tipo de emprendimiento tiene una gran incidencia y potencial para generar escenarios de paz y procesos de resiliencia en territorios afectados por el conflicto armado, ya que promueven prácticas y generan herramientas y dispositivos que contribuyen a mejorar la calidad de vida de los seres humanos, la superación de la pobreza o el acceso a derechos como la educación, la salud y la sostenibilidad ambiental.

La mayoría de los proyectos de los emprendedores sociales propician la conciencia de nuestras relaciones como sociedad y de los cambios que se deben realizar para construir una sociedad más equitativa, esto incide directamente en reconocer y enfrentar los diferentes tipos de violencia que hay en la sociedad, lo que coadyuva a que replanteemos nuestro accionar y busquemos soluciones para poner fin a la violencia y construir culturas de paz.

El emprendimiento cultural plantea y desarrolla un cambio de modelo económico donde se producen, transforman, circulan y consumen bienes intangibles, que se enriquecen y proliferan cuando se comparten, esto hace que sea una producción sostenible.

\begin{abstract}
Vivimos inmersos en un nuevo modelo productivo. Hemos pasado del modelo industrial al sector servicios, más del $80 \%$ de la población desempeña trabajos de oficina y estamos empezando a darnos cuenta de que son la innovación y la gestión del conocimiento los motores de la economía. Utilizamos lo intangible como materia prima. Si en el caso del emprendimiento social ya se planteaba la cuestión, en el caso del emprendimiento cultural es la clave: el valor inmaterial determina lo material. (Pizarro \& Rodero, s/f).
\end{abstract}

Los emprendimientos culturales contribuyen al crecimiento económico de manera armónica entre la sociedad y la naturaleza, al tiempo que empoderan a las comunidades, construyen y fortalecen identidades, visibilizan problemas sociales, y forman seres sensibles y empáticos con el desarrollo de la creatividad y la generación de alternativas productivas, elementos fundamentales para la transformación de escenarios de conflicto.

El emprendimiento social y cultural implica el desarrollo de procesos de innovación social y el alcance de la sostenibilidad económica; por lo tanto, es necesaria la implementación de herramientas empresariales, Pizarro y Rodero (s/f) argumentan lo siguiente: 
El emprendimiento social o la creación de empresas como medio para la transformación social nace de la SUMA de las inquietudes propias del Tercer Sector (el trabajo con colectivos en riesgo de exclusión social, el afán de transformación...) con las herramientas propias del sector empresarial (sostenibilidad, técnicas de mercado, estrategias de financiación, servicio al cliente...).

En los emprendimientos sociales y culturales, la adecuada implementación de herramientas empresariales: la planeación estratégica, la estructura organizacional, la mercadotecnia, la comunicación, la gestión de proyectos y la financiación, son indispensables para alcanzar el impacto social que plantean este tipo de organizaciones, debido a que con ellas se concretan, de manera organizada, eficiente y efectiva la gestión de procesos; por estas razones se puso en marcha el proyecto Fortalece Cultura Caldas.

A continuación, se evidencia el desarrollo y los resultados obtenidos en el proyecto Fortalece Cultura Caldas, con especial énfasis en la importancia de fortalecer las herramientas empresariales de los emprendimientos y propuestas sociales y culturales para el desarrollo de acciones eficientes, que contribuyan a la construcción de culturas de paz. En primer lugar, se toma en cuenta el contexto de actuación, el contraste entre los escenarios de conflicto y las prácticas de cultura como formas de resistencia en Anserma, Viterbo y Aguadas (Caldas); en segundo lugar, se presenta el sustento teórico del análisis sobre la relación entre el emprendimiento cultural y social y la resiliencia, el papel de la gestión cultural en estos tipos de emprendimiento, la asociación y el trabajo colaborativo como parte de la resistencia de las comunidades; en tercer lugar, se describe la ruta metodológica que siguió el proyecto de investigación y formación; por último, se evidencian los resultados y discusiones obtenidos en el proceso para, finalmente, llegar a las conclusiones.

\section{Entre el conflicto y la riqueza cultural y social}

En los años ochenta, el departamento de Caldas, Colombia, gozaba de estabilidad económica gracias a la bonanza cafetera, sus habitantes tenían una buena calidad de vida $y$, por estas razones, había logrado poner restricciones a las estrategias de inserción de los grupos armados, quienes usaban este territorio únicamente como corredor de paso (Palacio \& Cifuentes, 2005). Sin embargo, desde los años noventa, el conflicto armado en Colombia adquirió una nueva dinámica al expandirse y agudizar la violencia en diversos territorios, entre los que se encontraban Caldas y la región cafetera, esta inserción del conflicto armado en el departamento caldense coincidió con la crisis del sector agrícola, el derrumbe de la economía cafetera y, como consecuencia, la disminución de la calidad de vida, Rettberg (2012) explica este fenómeno: 
La conflictividad en la región cafetera está ligada a la pobreza de las familias campesinas e indígenas y al debilitamiento de las instituciones que por casi un siglo habían sustentado el desarrollo social y económico: La pobreza y el debilitamiento de la Federación [Nacional de Cafeteros] dejaron un vacío institucional que abrió ventanas de oportunidad para la penetración de las estratégicas tierras cafeteras por parte de grupos armados ilegales (p. 86).

Grupos guerrilleros, paramilitares y narcotraficantes aprovecharon la crisis económica que empezaba a afectar a la población de la región cafetera, se introdujeron al departamento de Caldas para operar el negocio más lucrativo y despiadado: la guerra; se desató una confrontación armada donde se disputó el dominio territorial, dejó pueblos abandonados, violaciones a los derechos humanos, y transformaciones ambientales y económicas debido a los cultivos ilícitos, el comercio de drogas y el auge de la explotación minera a manos de multinacionales extranjeras y grupos ilegales.

En Caldas el desplazamiento de las poblaciones ha sido una de las principales estrategias de los grupos armados para obtener el control y el poder en los territorios, por esta razón han infundido terror en la población, al cometer atentados, tomas armadas, secuestros, amenazas, homicidios y violaciones a niños y mujeres, lo que dejó como saldo 7469351 de personas desplazadas, 114 503 sin bienes muebles o inmuebles y 9419 despojadas de manera forzada de sus tierras (Unidad de Victimas, 2019). Estos hechos violentos han agudizado la pobreza en el departamento, ocasionaron que miles de familias perdieran sus oportunidades de obtener una vivienda, educación y trabajo digno.

En la actualidad, con la firma de los acuerdos para la construcción de una paz estable y duradera entre la insurgencia armada y el gobierno nacional colombiano, aún existen conflictos ligados a los intereses económicos e impactos de la confrontación armada, que están en la órbita de situaciones clave como la reparación a las víctimas y el retorno y la restitución de tierras. Estos procesos atraen buena parte de la atención institucional y de la agenda de investigación social en las universidades regionales.

La transición que se espera obtener del paso del conflicto armado a la construcción de escenarios de paz en Colombia es un proceso a largo plazo, que implica una transformación cultural y la apertura de oportunidades inclusivas educativas y económicas para las poblaciones vulnerables, esto se podrá materializar con la construcción de políticas nacionales e instituciones más democráticas, sostenibles, colaborativas y con sentido social.

En este proceso de transformación cultural y de apertura de oportunidades laborales y educativas en contextos golpeados por la violencia en Caldas, organizaciones sociales y culturales que creyeron en el poder transformador del arte, la cultura y el patrimonio, han trabajado desde que los conflictos alcanzaron su etapa más crítica. Estas organizaciones decidieron cambiar el pensamiento y el 
rumbo de vida de los niños, de los jóvenes y de los adultos; transmitieron saberes, valores y sensibilidad, lograron recuperar vidas humanas de la guerra, resistieron al conflicto, proyectaron en su contexto nacional e internacional la identidad cultural de su pueblo y abrieron posibilidades a otro tipo de economías solidarias y sociales.

Destacan los festivales del sombrero aguadeño y el Festival Nacional del Pasillo Colombiano en el municipio de Aguadas, ambos eventos fueron declarados patrimonio cultural de la nación; en ellos se han organizado, por generaciones, las artesanas y artesanos del municipio, al tiempo que se ha generado una fuerte identidad cultural. En municipios como Anserma y Viterbo se han apropiado de la cultura cafetera, lo que generó de turismo cultural, creación de artesanías en café y la producción de café a través de asociaciones. Gracias a estos procesos, las organizaciones culturales y sociales han trabajado en la reparación y fortalecimiento del tejido social, según Mouly y Giménez (2017) la cultura, el arte y el patrimonio cultural inmaterial contribuyen a la construcción de escenarios de paz durante el posconflicto en tres sentidos:

El primero, puede propiciar el mayor involucramiento de la población en el proceso y la mayor apropiación del mismo; segundo, puede ayudar a reparar las relaciones interpersonales destruidas por el conflicto armado y facilitar la reconciliación al promover una identidad común y fomentar la colaboración; tercero, puede ayudar a reducir la violencia cultural y estructural (p. 285).

Por estas razones, la labor de las organizaciones culturales y sociales es fundamental en un proceso de pos acuerdo; sin embargo, la gestión organizacional de estas iniciativas es vulnerable porque sus apuestas se centran en los objetivos, pero descuidan la estructura orgánica y operativa, la administración, y la gestión de las organizaciones. Desafortunadamente tienen dificultades para trabajar en red y para generar relaciones con el sector público y privado, lo que limita sus posibilidades de sustentabilidad y la generación de empleos dignos para sus integrantes, de alto impacto, con mayor alcance a nivel social, económico y cultural. Estas debilidades internas de las organizaciones, sumadas a la disminución presupuestal de los fondos públicos para la cultura, y la falta de responsabilidad social empresarial por parte del sector privado, ponen en riesgo prácticas y tradiciones culturales con gran valor identitario y social.

\section{El emprendimiento cultural como medio de resiliencia en escenarios de posconflicto}

Cada vez que se asesinaba a un líder o lideresa, que se violaba a un menor o a una mujer, que se detonaba una bomba, que se hacían tomas guerrilleras y paramilitares, que se amenazaba a un joven, que se manchaban las fachadas de 
frases llenas de odio y miedo, que se cerraban los colegios, que se secuestraba y, en fin, que se saqueaba la vida, los territorios se despojaban de su alegría, se marchitaban por el dolor y el abandono. Pero en paralelo resurgían voces que gritaban para encontrar resiliencia, esperanza y resistencia, voces que querían recuperar sus cuerpos, territorios y comunidades.

En la búsqueda por reparar el impacto que ha dejado la violencia, la gestión cultural, el trabajo social, las artes, la pedagogía popular y el emprendimiento cultural y social, son una alternativa para que la sociedad avance en la superación de los traumas de la guerra y en la reconstrucción del tejido social. A través del emprendimiento y la gestión cultural se han entretejido los vínculos comunitarios, también se ha generado identidad y arraigo, mayor reconocimiento y valoración del territorio y sus habitantes; se ha fortalecido la convivencia, el desarrollo local, y la gestión de espacios de participación ciudadana, los cuales han sido clave para el empoderamiento colectivo e individual y la dinamización comunitaria.

Garantizar que estos valores sociales y culturales se expandan y transciendan en la construcción de un saber vivir para las comunidades, implica fortalecer los procesos de gestión de las organizaciones que los impulsan; no todos los proyectos culturales y sociales serán autosostenibles o rentables, pero sí es necesario reconocer que adquirir herramientas administrativas, de gestión, comunicación, y de trabajo colaborativo es indispensable para cualquier organización, no solo porque posibilitan la generación de estrategias de circulación y comercialización para proyectos con potencial económico, sino también porque se organizan mejor los procesos, son más eficientes en la generación de servicios o bienes de calidad, viables y colaborativos. También se fomenta con mayor impacto la participación de las comunidades de interés, se promocionan, en diferentes niveles, los bienes o procesos realizados, se generan redes de alianzas y se garantizan los actores que trabajan por transformar el contexto social y cultural para que puedan ser recompensados dignamente por su trabajo.

El emprendimiento en el sector cultural y social surge de la necesidad de contrarrestar el efecto negativo de la actual crisis económica para la sostenibilidad financiera de las organizaciones o procesos culturales y sociales que se dirigen a comunidades en riesgo de exclusión social, y brindan respuestas innovadoras a problemáticas sociales a través de "la búsqueda de herramientas económicas y empresariales que puedan ser una alternativa eficaz a la dependencia de las subvenciones, así como la expansión internacional de las redes de emprendimiento social y la escalabilidad" (Pizarro \& Rodero, s/f).

La esencia del emprendimiento está en su capacidad de generar valor social, cultural o ambiental; la aplicación de herramientas y estrategias empresariales deben responder a su sentido social, esto implica que su estructura organizacional, sus formas de producción, gestión, comunicación, distribución y comercialización 
deben realizarse bajo principios solidarios y equitativos, como la colaboración, la participación, el acceso cultural, la armonía con el territorio y la cohesión social.

Según Ospina (2018) "Los emprendimientos sociales, aunque cuentan con los criterios comunes de cualquier ruta de negocio, tienen un interés particular en el medio ambiente, en el desarrollo social y, principalmente, en el desarrollo local" (p.66). En Colombia, quienes han facilitado el desarrollo desde lo económico, político y social, a partir de la reparación comunitaria, familiar e individual son los colectivos de tejedoras, artesanos, líderes y lideresas, las iniciativas de danza, teatro y artes en general, las asociaciones de mujeres, casas de la cultura y grupos sociales, (ligados a procesos de gestión y emprendimiento cultural).

Lo importante es que emprender desde la cultura no solo reactiva las economías locales, sino que también se rehabilitan las sociedades y los territorios con la participación, el dinamismo, el empoderamiento, los afectos y la autonomía. Con los procesos de gestión y emprendimiento cultural se fortalecen los espacios y las víctimas del conflicto armado colombiano, también avanza la construcción de paz y la finalización o apaciguamiento del conflicto. Mediante estrategias culturales, creativas y artísticas y apuestas poético-políticas se estimula la reconciliación, la paz, el perdón y la convivencia, no solo han sido medios para reparar el daño, sino también han sido herramientas para prevenir la reproducción de la guerra.

Uno de los puntos centrales de este texto es el potencial de la cultura en la construcción de paz, entendida como el "conjunto de acciones (en el corto, medio y largo plazo) que permiten a una sociedad prevenir, gestionar y resolver el conflicto -a través de sus propias capacidades- sin recurrir al uso de la violencia" (IECAH, 2014). Si bien las artes y la cultura no son la solución a todas las problemáticas, sí posibilitan que los conflictos se gestionen desde la humanización y la empatía que aportan a las personas. Además, propicia el progreso económico por medio del saber, los oficios, las potencialidades del territorio y las costumbres, tal como se plantea en la Ley de Fomento a la Cultura del Emprendimiento en Colombia (Ley $\mathrm{N}^{\circ} 1014,2006$ ) donde se define al emprendimiento como:

Una manera de pensar y actuar orientada hacia la creación de riqueza. Es una forma de pensar, razonar y actuar centrada en las oportunidades, planteada con visión global y llevada a cabo mediante un liderazgo equilibrado y la gestión de un riesgo calculado, su resultado es la creación de valor que beneficia a la empresa, la economía y la sociedad (Artículo 1).

En conclusión, el fortalecimiento de las organizaciones y emprendimientos culturales y sociales les brindará a las comunidades posibilidades de resiliencia desde la participación, la confianza, el respeto y el desarrollo local. 


\section{El rol del gestor cultural en el emprendimiento cultural y social}

El gestor cultural es un agente social que reconoce y comprende (como se verá más adelante, puede ayudar a la transformación de la sociedad y generar tejidos sociales) las particularidades de las comunidades, procura encaminar su quehacer (o su rol profesional, si se quiere) a propiciar la gestación, germinación y desarrollo de procesos culturales, al igual que la construcción de una sociedad donde la cultura sea la fuente de cohesión social y el eje fundamental de su desarrollo. Gracias a su formación, cuenta con la capacidad y las herramientas para implementar acciones específicas que contribuyan, a partir de la dinamización, promoción y fortalecimiento de organizaciones, a la transformación de las estructuras culturales y al desarrollo de procesos participativos y democráticos que posibiliten a las comunidades el acceso a los derechos culturales (SECAB, 1994).

La misión del gestor cultural es su labor permanente de mediación social para la construcción incesante de un mundo donde el hombre crezca en libertad y cultural, despliegue todo su potencial como fuente de identidad, cohesión, referencia y la constante búsqueda de satisfacción de sus inagotables deseos y demandas. (Para un mundo posible: Programa Nacional de Formación en Gestión Cultural en Guédez \& Menéndez, 1994, p. 263).

En escenarios o territorios de conflicto, donde la violencia desquebraja el tejido social y anula las redes de cooperación comunales, el papel del gestor cultural consiste en servir de mediador entre la resolución del conflicto armado y las necesidades del contexto histórico-cultural que demanda una transformación (Nató, Rodríguez Querejazu, \& Carvajal como se citó en Yáñez 2013). El gestor cultural no solo debe comprender las dinámicas específicas de cada contexto, también debe generar mecanismos de mediación cultural y artística que promuevan los encuentros y las relaciones recíprocas entre los miembros de una sociedad para el intercambio de significados.

El programa Fortalece Cultura Caldas, por ejemplo, propició, a través de métodos enfocados en las particularidades del contexto de cada municipio (Anserma, Viterbo y Aguadas) y de cada organización, espacios de encuentro, circulación y promoción de iniciativas que se gestaron al interior de los municipios y que aportaron al desarrollo económico, turístico y social de cada territorio. La labor de gestión se apoyó en el fortalecimiento de economías locales, en la promoción de estrategias culturales, creativas y artísticas que originaron diversos espacios de reconciliación, convivencia y dinamización de la vida social. En otras palabras, una reconstrucción del tejido social.

Por otra parte, el papel del gestor cultural debe comprenderse, además, como generador de espacios de resistencia y re-existencia, en su función 
subversiva de la realidad social. Lo anterior debido a que en su función social y profesional procura el fortalecimiento de la cultura como eje central de los procesos sociales con el propósito de que se generen nuevas formas de habitar y estar con los otros (Yañez, 2010), así como nuevos mecanismos de participación política que tienen como finalidad la transformación de la comunidad y la conformación de experiencias de vida desde la estética de la existencia.

El rol del gestor cultural en el emprendimiento (tanto en el emprendimiento cultural y social, como en espacios de conflicto armado) se orienta a través de tres funciones clave. La primera, su figura de mediador social que posibilita el encuentro y el reconocimiento del otro en un espacio dialógico. La segunda, la de dinamizador que pone en tensión y conversación los diferentes elementos que constituyen la realidad cultural. Y la tercera, es creador de herramientas y metodologías creativas, artísticas y simbólicas que operan para recuperar el universo significativo y el tejido social.

\section{La asociatividad y el trabajo colaborativo como forma de sostenibilidad}

Los emprendimientos culturales y sociales se organizan bajo estructuras económicas solidarias, en coordinación con fundaciones, asociaciones, cooperativas y corporaciones, que son "originadas en la libre asociación de los trabajadores, con base en principios de autogestión, cooperación, eficiencia y viabilidad" (Di Meglio, Lisa, Pacheco \& Tueros, 2008, p. 23).

Esta unión de esfuerzos trata de resolver problemas comunes con el diseño de estrategias productivas y democráticas, mediante soluciones que crean y ofrecen valor social, ambiental, cultural y económico, no solo a su contexto inmediato, sino también al interior de la organización. Estas asociaciones representan una oportunidad para mejorar las condiciones laborales, la calidad de vida y la formación integral de sus participantes, este tipo de emprendimientos agrupa a "los individuos excluidos del mercado de trabajo o motivados por la fuerza de sus convicciones y en búsqueda de alternativas colectivas de supervivencia" (Di Meglio et al., 2008, p. 23).

Los emprendimientos sociales y culturales deben lograr la sostenibilidad financiera, generar los recursos para garantizar empleos dignos y la continuidad en el desarrollo de procesos culturales y sociales de calidad. Aunque el capital económico no es su principal fin, sí es una herramienta para resolver el problema social, cultural o ambiental que intenta transformar la organización con la cohesión comunitaria.

Para las organizaciones y los emprendimientos sociales y comunitarios ser sostenibles es un proceso complejo, debido a dinámicas tanto externas como internas, la incertidumbre del sector cultural y social, y la falta de políticas 
regionales y locales que fomenten, acompañen, apoyen, e impulsen este tipo de emprendimientos que valoren su capacidad de rentabilidad social, son dos factores que amenazan su desarrollo y crecimiento. La cultura de la individualidad y de la competencia que aún persiste en el ecosistema emprendedor y empresarial en Colombia, en especial en departamentos como Caldas, limitan el campo de acción de los pequeños emprendedores, así como sus recursos, no solo financieros, sino técnicos y de conocimientos, y su impacto, al no orientar acciones que se enfoquen en un mismo objetivo.

A pesar de que la naturaleza del emprendimiento social y cultural es asociativa, el trabajo colaborativo como una estrategia para generar procesos más eficientes y sostenibles a nivel financiero y de continuidad, aún es un reto para estas organizaciones. Aplicar prácticas como la colaboración a nivel interno y externo es un trabajo que requiere de un cambio de paradigma en el ecosistema cultural; pasar de la competencia a la colaboración, de consumidores a participantes, de colaboradores a co-creadores, de la acumulación de información individual a compartir conocimientos para formar equipo entre las distintas organizaciones.

Según Moizo y Díaz (2015) el trabajo colaborativo requiere de la "generosidad" del sector, de un trabajo colaborativo entre pares (...). Es decir, poner a disposición nuestros saberes, modelos, herramientas en pos de generar una base sólida de recursos y una comunidad activa en la cual apoyarse (p. 86).

El trabajo en colaboración fortalece la unión de esfuerzos, estrategias y recursos para que las organizaciones cumplan de manera eficiente objetivos comunes, que beneficien no solo a las organizaciones implicadas, sino que abran camino a todo el ecosistema cultural. Entonces será posible crear nuevos mercados, estrategias de circulación y de comercialización, formar comunidades participantes y generar bases de conocimiento compartido y accesible, además de fortalecer entre sí los procesos individuales. Sus acciones se encaminan a generar impactos de largo alcance para atender desde diferentes frentes, pero de manera conjunta, la misma necesidad.

La colaboración y las interacciones que se crean en internet ayudan a que las organizaciones y emprendimientos sociales y culturales generen redes de trabajo a nivel local e internacional para ampliar sus campos de acción y replicar procesos locales en diversos contextos. Ramírez y Lay (2015) explican las fortalezas y los desafíos del trabajo en red.

El trabajo en red facilita la unión de sinergias tanto a nivel local como internacional. Este tipo de trabajo nos permite ser flexibles pero también robustos, facilita la integración de elementos y la adaptación de los proyectos ante situaciones adversas o complicadas, pero también ayuda a que la red 
pueda ir creciendo y ampliando sus horizontes al incorporar nuevos miembros (Brun et al. 2008). Como sea, el trabajo en red, también plantea algunos desafíos, en primer lugar se debe ser flexible y con capacidad de moldearse a las circunstancias cambiantes. De igual forma, se debe mantener una comunicación constante entre los miembros de la red (p. 4).

El trabajo colaborativo y las redes en los emprendimientos culturales y sociales son efectivos en la medida en que se logre comprender las dinámicas de trabajar bajo los principios de democracia y participación. Donde el liderazgo es compartido, los consensos entre los integrantes de la organización y red son fundamentales para la toma de decisiones. La comunicación debe fluir de manera horizontal, esto no quiere decir que los procesos se retrasen por no contar con la participación de algún integrante, este tipo de trabajo implica todo lo contrario, conlleva a contar con un grupo de personas con capacidades diversas y complementarias del mismo nivel y capacidad de decisión.

Las redes posibilitan no solo que se generen conocimientos, productos, servicios o bienes culturales con la integración de recursos individuales, sino que posibilitan su reproducción, distribución y acceso, lo que amplía las posibilidades de sostenibilidad de los emprendimientos.

\section{Metodología: tejer la paz en la subregión norte y occidente de Caldas}

Fortalece Cultura Caldas es un proyecto de investigación y formación de emprendimiento cultural y social desarrollado en un contexto de posconflicto, su objetivo general consistió en fortalecer la organización y gestión de los procesos sociales y artísticos que trabajan en la construcción de paz en las subregiones norte y occidente de Caldas, específicamente en los municipios de Aguadas, Anserma y Viterbo, a partir de la creación de espacios colaborativos que atienden necesidades de formación empresarial, e identifican posibilidades de trabajo en red y de relacionamiento interinstitucional.

Este propósito se materializó a partir de tres objetivos específicos; en primer lugar, se diseñó y desarrolló una metodología para la realización de laboratorios de co-creación donde las organizaciones sociales y artísticas analizaron su gestión y propusieron soluciones a las dificultades de sus contextos; en segundo lugar, se identificaron las necesidades organizacionales de las iniciativas sociales y artísticas que trabajan en la construcción de paz y, por último, se fomentó la articulación entre las organizaciones de los municipios implicados mediante el intercambio de experiencias y el relacionamiento.

Para tener un acercamiento a los sectores culturales y sociales de los municipios de Anserma, Viterbo y Aguadas se emplearon estrategias y metodologías cercanas y sensibles de acuerdo con las dinámicas del sector y los contextos sociales de la región. Al principio, el proyecto consistió en una 
investigación de carácter cualitativo, con el fin de realizar un diagnóstico del sector cultural y de las organizaciones sociales y culturales de la subregión, se empleó una metodología de acción participativa. Como segunda fase se llevaron a cabo los procesos de formación y facilitación en emprendimiento cultural y social a partir de talleres prácticos, espacios participativos de co-creación, asesorías personalizadas, espacios de networking, y herramientas de animación sociocultural.

En su fase de investigación y formación el proyecto se desarrolló a partir de cuatro etapas: acercamiento a las comunidades, sensibilización al sector cultural, fortalecimiento a las organizaciones inscritas en el proyecto, y circulación de los emprendimientos de cada municipio.

La primera medida fue un proceso de acercamiento para que el equipo desarrollara un diagnóstico colectivo e individual del sector cultural. Esta breve investigación se desarrolló a través de una revisión literaria y mediante talleres con las organizaciones participantes en el proceso de formación, para diseñar un plan de trabajo ajustado a sus necesidades particulares y fortalezas, en su quehacer social y cultural.

En segunda instancia, con las organizaciones de los municipios de Anserma, Viterbo y Aguadas, se desarrollaron diferentes talleres que brindaron contenidos prácticos para socializar las líneas básicas y temas base sobre el emprendimiento cultural. Con estos espacios las organizaciones reflexionaron y analizaron los retos que existen en el municipio, departamento y país, a la hora de emprender. A través de estos se consiguió generar cercanía con las organizaciones y sensibilizarlas sobre conceptos como el proyecto de vida, la innovación y la creatividad.

En tercera instancia, se desarrollaron los módulos de modelo de negocios, estructura organizacional, comunicación, elaboración de proyectos y financiación. Los contenidos de los módulos se transmitieron a través de talleres, asesorías personalizadas y grupales, cafés culturales y clínicas de proyectos, con los cuales se brindaron herramientas para el desarrollo $y$ fortalecimiento de las organizaciones y sus proyectos.

Finalmente, se desarrolló "Tejidos Caldas", un espacio para la exhibición, promoción y circulación de bienes y servicios culturales de las organizaciones de Caldas (norte y occidente), aquí se socializaron los resultados del proyecto Fortalece Cultura y se articularon las organizaciones participantes con la institucionalidad y los diferentes actores de sus contextos.

\section{Resultados}

Al realizar el diagnóstico para identificar el estado actual de las organizaciones y emprendimientos sociales y culturales, se tomó en cuenta la participación 
económica de los municipios de Anserma, Viterbo y Aguadas en el departamento de Caldas, también el aporte y la participación del sector cultural y social en el desarrollo económico de estos municipios, en este contexto se encontró que:

Según la Cámara de Comercio de Manizales por Caldas (CCMPC,2017), el municipio de Anserma, que cuenta con una población 33669 se ubica en el quinto grado de importancia económica a nivel municipal ya que se encuentra en el rango entre 177 y 302 miles de millones de pesos corrientes de valor agregado, del cual el sector de servicios sociales aporta $\$ 13$ (miles de millones de pesos corrientes), contando con un total de 31 empresas o establecimientos comerciales del sector servicios comunales y sociales. Por otro lado, el municipio de Viterbo que cuenta con una población total de 12438 personas se ubica en el sexto grado de importancia económica a nivel departamental ya que se ubica en el rango entre 84 y 176 miles de millones de pesos corrientes de valor agregado, del cual el sector de servicios sociales aporta $\$ 5$ (miles de millones de pesos corrientes), contando con un total de nueve empresas del sector servicios comunales y sociales. $Y$, finalmente, Aguadas, con una población 21865 personas se ubica en un sexto grado de importancia económica a nivel municipal ya que se ubica en el rango entre 84 y 176 miles de millones de pesos corrientes de valor agregado, del cual el sector de servicios sociales aporta $\$ 8$ (miles de millones de pesos corrientes), contando con un total de 24 empresas del sector servicios comunales y sociales (CCMPC, 2017).

Se identificó que estas empresas y emprendimientos sociales impulsaron sus proyectos, principalmente, a través de fondos públicos como el impuesto nacional al consumo. Gracias a este impuesto, el municipio de Anserma ha desarrollado proyectos como "Impacto cultural del café, en el desarrollo de la música tradicional en el eje cafetero" aprobado por \$7 500000 y cofinanciado con \$2 500000 para obtener un total de $\$ 10000000$. Otro proyecto financiado por medio de este fondo fue "Primeros auxilios del centro cultural y biblioteca pública Arturo y Roberto Restrepo del municipio de Anserma Caldas", aprobado por \$12 000000 y cofinanciado con \$8 00000 para llegar a un total de \$20000 000 .

Se identificó muy poca participación por parte de las organizaciones en fondos de financiación como el Sistema General de Regalías y las convocatorias del Ministerio de Cultura de Colombia. A partir de este fenómeno y de las condiciones del sector social y cultural frente a conocimientos en formulación y gestión de proyectos, se deduce que uno de los factores que influyen en la baja participación en este tipo de financiación se debe a las debilidades en la formulación de proyectos y la apatía que presentan los colectivos socioculturales frente a procesos y trámites administrativos. Así, entre 2014 y 2015 las organizaciones sociales y culturales de Viterbo no obtuvieron aprobación de sus proyectos en las convocatorias de los programas de estímulos y concertación del Ministerio de Cultura de Colombia.

El panorama del Sistema General de Regalías (SGR) no se escapa al escenario del Ministerio de Cultura, los proyectos que se invierten con el SGR no 
pertenecen al sector social y cultural. Las principales causas por las que ocurre este suceso se debe a la dificultad de acceso a la información, priorización de proyectos como la construcción de escenarios deportivos y la recuperación de la malla vial en la zona urbana de los municipios de Anserma y Viterbo.

Por fortuna, para el uso de los impuestos nacionales al consumo y la estampilla pro-cultura, la situación no ha sido desfavorable. Gracias a los impuestos nacionales al consumo se han financiado proyectos culturales $y$ patrimoniales como el proyecto "Listado preliminar inventario y registro de 10 bienes inmuebles de valor patrimonial ubicados en la vereda el porvenir zona principal del paisaje cultural cafetero del municipio de Viterbo". La estampilla procultura ha financiado programas de escuelas municipales de música en Viterbo.

El panorama general del municipio de Aguadas nos muestra que existe una oferta cultural reconocida a nivel nacional y que a esta oferta la respalda una administración pública que busca fortalecer el emprendimiento cultural. Las organizaciones culturales y sociales del municipio participan activamente en convocatorias públicas, estas son beneficiadas con recursos de Estampilla Procultura, del Impuesto Nacional de Consumo, del Sistema General de Regalías y del Ministerio de Cultura.

Este primer diagnóstico arrojó una evidente necesidad, por parte de las organizaciones sociales y culturales, de adquirir herramientas y conocimientos administrativos, de gestión y comunicación para reconocer y estructurar fuentes de financiamiento que sean rentables y estables dentro del mercado; sin embargo, para llegar a este estado se espera que haya un impacto a largo plazo, debido a que es necesario, en primer lugar, fortalecer la organización y la gestión interna y externa de los emprendimientos.

Por esta razón, Fortalece cultura convocó y contó con la participaron de 30 organizaciones pertenecientes al sector cultural y social (15 de la subregión norte y 15 de la subregión occidente), conformadas por alrededor de 150 personas, entre las que se encuentran: mesas de víctimas, juntas de acción comunal, fundaciones, artistas musicales, fundaciones teatrales, plásticos, asociaciones de artesanos, iniciativas de gastronomía y de agricultura.

Estas organizaciones y proyectos, a partir de los contenidos que recibieron en los espacios de formación y de networking, identificaron y definieron su modelo de negocio, estructura organizacional, estrategias de comunicación, herramientas para la comercialización y fuentes de financiación; además, adquirieron competencias para armar equipos multidisciplinarios a través del trabajo en colaboración, de estructurar costos, y conocimientos sobre fuentes para la sostenibilidad de sus organizaciones y de la elaboración de proyectos.

Este proceso de fortalecimiento y crecimiento empresarial estuvo a cargo de profesionales de áreas en ciencias sociales: gestión cultural, comunicación y 
psicología, quienes cuentan con experiencia y sensibilidad en temas culturales y de construcción de paz.

En el transcurso de la etapa de fortalecimiento se generaron espacios de networking denominados "Café Cultural" y "La colmena", desarrollados en los tres municipios. En ambos espacios los emprendedores participantes se asociaron para fomentar el intercambio de conocimientos, experiencias y la generación de alianzas estratégicas. Estos espacios reunieron a los emprendedores de Anserma y Viterbo con el fin de promover el trabajo regional.

El proyecto denominado "Tejidos", produjo espacios para la circulación y promoción cultural; tuvo dos versiones, una de ellas se realizó en el municipio de Aguadas y la segunda se desarrolló en los municipios de Anserma y Viterbo. Con estos espacios se evidenciaron las experiencias de las organizaciones partícipes en todo el proceso, se promovió el trabajo colaborativo entre el sector cultural y social con los sectores productivos y las instituciones gubernamentales.

Fortalece Cultura Caldas diseñó un portafolio que integra, visibiliza y promociona la oferta de las organizaciones sociales y culturales de la subregión norte y occidente de Caldas, esta herramienta es una guía que invita a propios y foráneos a disfrutar y vivir nuevas experiencias a partir de los bienes y servicios culturales tradicionales y novedosos de los municipios de Anserma, Viterbo y Aguadas.

Con la puesta en marcha de este proyecto hubo un acercamiento con los contextos locales, además de hacer un diagnóstico individual y colectivo del sector cultural y las organizaciones partícipes en el proceso de formación.También se diseñó un plan de trabajo ajustado a las necesidades particulares, a los requisitos de sostenibilidad y al entorno de violencia que vive cada municipio.

\section{Discusión: retos de las organizaciones y emprendimientos culturales y sociales}

Las organizaciones y los emprendimientos sociales y culturales cuyo escenario de actuación se limita a territorios y poblaciones reducidas como los municipios de Aguadas, Viterbo y Anserma, enfrentan la dificultad de no contar con espacios suficientes para la distribución y comercialización de sus servicios culturales. Las posibilidades de llegar a más participantes son limitadas; por lo tanto, su sostenibilidad financiera depende de esporádicos apoyos gubernamentales, lo cual desciende en casos de precariedad y autoexploración laboral.

Por estas razones es necesario que los emprendedores empiecen a trabajar en proyectos de región o subregión (norte y occidente caldense), donde haya redes que homologuen los procesos a favor de objetivos comunes, que se generen nuevos mercados y modos de producción más colaborativos que sirvan como base para el crecimiento de emprendimientos que cuentan con trayectoria y oferta de 
calidad, y que abran un camino de oportunidades para los emprendedores que inician su proceso.

A partir de proyectos colaborativos y la apertura de los espacios institucionales las prácticas colaborativas van a facilitar la apertura a nuevos modelos, a nuevas narrativas culturales que recojan una realidad abierta a las expectativas y necesidades de comunicación y creación de los ciudadanos (Insa, 2011, p.12).

Los procesos colaborativos implican prácticas de innovación cuando se transforman en una necesidad colectiva, generan otras formas de organización, producción y circulación, es decir, metodologías o sistemas de gestión que se ajustan a las dinámicas del sector cultural y social, a las necesidades de las comunidades implicadas y a los mercados. De este modo la innovación es una manera de crear valor para impulsar la calidad de vida de una comunidad.

La creatividad cultural y/o la innovación como actividades de la economía cultural no solo generan valor económico sino que estimulan la aparición de nuevas ideas y/o tecnologías, colaborando fundamentalmente en los procesos de cambio y transformación de la sociedad. (Moizo \& Díaz, 2015, p. 86).

Además de redes de trabajo colaborativo, se deben crear estrategias aterrizadas y coherentes a las realidades sociales de los emprendimientos de la subregión norte y occidente de Caldas, con el objetivo de seguir fortaleciéndolos a nivel organizacional y establecer lazos de reciprocidad, y no de competencia, que les den condiciones de vida digna y comunitaria. La aplicación de la innovación en los bienes, servicios y procesos de estas organizaciones sociales y culturales es indispensable para una oferta de calidad que responda a las verdaderas necesidades de las comunidades participantes.

\section{Conclusiones}

La capacitación en herramientas empresariales y de gestión debe convertirse en una actividad permanente en los emprendimientos sociales y culturales para estar en constante actualización y validar en la práctica su desarrollo. Esta práctica es uno de los pilares fundamentales e indispensables en el emprendimiento debido a que a partir del conocimiento se crean estrategias innovadoras y colaborativas para enfrentar las dinámicas complejas e inciertas del sector cultural y la economía.

Trabajar en torno a la colaboración coadyuva a que los procesos de emprendimiento cultural sean más eficientes para los integrantes de la organización y su relación con otras organizaciones, pueden compartirse conocimientos, metodologías, técnicas $y$, en ocasiones, recursos financieros que benefician a diversos proyectos al mismo tiempo. Asimismo, posibilita la creación 
de redes y plataformas más amplias de promoción, circulación y comercialización de la oferta cultural que aporten al desarrollo regional.

El papel del gestor cultural en los territorios de conflicto -al entender las dinámicas de los contextos sociales y culturales- es el de generar espacios de formación y colaboración entre los actores y organizaciones culturales para el encuentro, la reconciliación, la convivencia, la dinamización y la cohesión de la vida social.

Fortalecer los emprendimientos sociales y culturales por medio de la gestión cultural organizada, colectiva, planeada y comunitaria, además de generar escenarios de paz, traerá a largo plazo transformaciones sociales en Colombia, debido a que las organizaciones culturales y sociales son las que fortalecen una economía basada en la colaboración y la solidaridad, lo cual es más eficiente y promueve valores de fraternidad y armonía entre los seres humanos y su entorno. Los emprendimientos promueven oportunidades y brindan perspectivas de vida a jóvenes y adultos, crean espacios colectivos que incluyen a quienes deseen sumarse, sin importar el pasado de sus integrantes.

Si bien es cierto que luego de ejecutarse el proyecto se requiere de un estudio más profundo y cuantitativo para determinar el crecimiento económico al interior de los emprendimientos, y el impacto positivo en la reducción de la violencia en los municipios, se puede afirmar que fortalecer las capacidades de auto-gestión de las organizaciones es una gran oportunidad para que accedan de manera asertiva a fuentes de financiación, a pesar de que en Colombia y en Caldas -tal como se mencionó anteriormente- uno de los principales obstáculos para que los emprendimientos gestionen sus proyectos desde subvenciones, donaciones y cooperaciones, es el bajo conocimiento que poseen para gestionar sus productos y recursos.

Una vez finalizado el proceso, las organizaciones participantes están en la capacidad de formular sus propios proyectos, conocer fuentes de financiación, comunicar de manera asertiva su emprendimiento, interactuar con sus públicos, planear estrategias de financiamiento, y trabajar colectiva y solidariamente con los otros.

Sin duda, estos son aprendizajes valiosos que ayudan a las organizaciones y municipios a acercarse al crecimiento económico y, aún mejor, ayudan a que su hacer social tenga un mayor impacto, sea más organizado y estratégico para lograr más y mejores cambios en sus contextos y en la sociedad en general.

\section{Referencias}

Bargsted, A. (2013). El emprendimiento social desde una mirada psicosocial. Civilizar Ciencias Sociales y Humanas, 13(25), pp. 121-132. 
Cámara de Comercio de Manizales por Caldas (CCMPC). (2017). Estudios Económicos, Fichas Municipales. Recuperado el 10 de abril de 2018, de http://estudios.ccmpc.org.co/fichas-municipales/.

Di Meglio, R. Lisa, M. Pacheco, M. \& Tueros, M. (coords). (2008). Programa Modular: Emprendimiento para pueblos indígenas Lima, Perú: Organización Internacional del Trabajo y Centro Internacional de Formación.

IECAH. Instituto de Estudios sobre conflictos y Acción Humanitaria. (2010). Construcción de la Paz. Recuperado el 8 de abril de 2019, de: https://www.iecah.org/index.php/investigacioncp.

Insa, J. R. (2011). Cultura 2020 ¿De qué queremos hablar?. Documento complementario elaborado dentro del proceso de reflexión de la Estrategia Zaragoza 2020. Ebropolis. Recuperado el 11 dejulio de 2018, de: http://www.ebropolis.es/files/File/Plan\%20Estratgico/culturaestrategia2020.pdf

Ley No 1014. Diario Oficial No. 46.164, Congreso de Colombia. De fomento a la cultura del emprendimiento. 27 de enero de 2006. De fomento a la cultura del emprendimiento.

Moizo, C. \& Díaz, B. (2015). Cap. 6. Innovar desde la Gestión. En Moresino, S. (Ed.). Salirse de la línea, aportes para la reflexión en torno a la gestión cultural en Uruguay. pp. 7-119. Montevideo, Uruguay: Ministerio de Educación y Cultura (MEC) o de los Centros MEC.

Mouly, C. \& Giménez, J. (2017). Oportunidades y desafíos del uso del patrimonio cultural inmaterial en la construcción de paz en el posconflicto. Implicaciones para Colombia. Estudios Políticos, 50, pp. 281-302. DOI: 10.17533/udea.espo.n50a15. Colombia: Universidad de Antioquia.

Ospina, D. A. (2018). Construcción de comunidades colaborativas desde el diseño y el emprendimiento endógeno. Revista EAN, 84, pp. 63-77. DOI https://doi.org/10.21158/01208160.n84.2018.1917.

Palacio, M. C., \& Cifuentes, M. R. (2005). El departamento de Caldas: su configuración como territorio de conflicto armado y desplazamiento 
forzado. [Versión electrónica]. Trabajo Social, No. 7, pp. 99-110. Colombia: Universidad Nacional.

Para un Mundo Posible: Programa Nacional de Formación en Gestión Cultural Colcultura - Colombia. 1995, p. En: Guédez, Víctor \& Menéndez, Carmen. Eds. (1994). Formación en gestión cultural. Convenio Andrés Bello. Santafé de Bogotá

Ramírez, D. \& Lay, T. (2015). Problemáticas legales de la gestión cultural en la era digital. Ponencia. Segundo Encuentro Nacional de Gestión Cultural. Diversidad, tradición e innovación en la gestión cultural. Tlaquepaque, Jalisco: Universidad de Guadalajara, Sistema de Universidad Virtual.

Rettberg, A. (2012). "Balas y tinto: conflicto armado en la zona cafetera Colombiana". En M, Samper y S, Topik. (Ed.), Crisis y transformaciones del mundo del café, dinámicas locales y estrategias nacionales en un periodo de adversidad e incertidumbre. Bogotá, Colombia: Editorial Pontificia Universidad Javeriana.

Rodero, E., \& Pizarro, E. (s.f.). Guía práctica de emprendimiento social y cultural. España: Universidad de Salamanca. Recuperado el 5 mayo de 2018, de: https://emprende.usal.es/esyc/autores.html.

Unidad de Víctimas. (2019). RNI - Red Nacional de Información. Colombia recuperado el 15 de mayo de 2019, de: https://cifras.unidadvictimas.gov.co/.

SECAB (1994). Guédez, V. \& Menéndez, C. (Ed.). Formación en Gestión Cultural. Colombia: Guadalupe Ltda.

Yáñez Canal, C. (2010). Viaje al "uno en la multiplicidad". La identidad personal y sus "sí mismos". Bogotá: Universidad Nacional de Colombia.

Yáñez Canal, C. (2013). La identidad del gestor cultural en América Latina: un camino en construcción. Bogotá: Universidad Nacional de Colombia. 